\title{
TRANSPARENCY IN RESPONSIBLE DESIGN: AVOIDING ENGINEERING OVERCONFIDENCE AND SUPPORTING SOCIETAL ACCEPTANCE
}

\author{
Vermaas, Pieter \\ Delft University of Technology
}

\begin{abstract}
In this contribution it is argued that in responsible design engineers should be transparent towards stakeholders about the goals they intend to realise with their designs. The emergence of responsible design in, e.g., value-sensitive design, design for values, social design, nudging and positive design, is to be welcomed. It has however the weakness of overconfidence which may lead engineers to suspend earlier commitments to society as given in engineering codes of conduct and ethics, and practices of seeking informed consent and taking blame. It is argued that these earlier commitments lead to the requirement that engineers should be transparent about the goals in responsible designs. Providing this transparency support moreover the societal acceptance of responsible design since it positions engineers doing responsible design as subscribing to values such as respect, honesty and trust. I illustrate the argument with a case of social design and a case of nudging.
\end{abstract}

Keywords: Social responsibility, Ethics, Communication, Engineering codes of conduct, Transparancy

\section{Contact:}

Vermaas, Pieter

Delft University of Technology

Philosophy

The Netherlands

p.e.vermaas@tudelft.nl 


\section{INTRODUCTION}

Responsible design, the theme adopted for the ICED 2019 Conference, is representative of what may be called a societal turn in engineering. Although already present for a longer period, as in for instance participatory design, especially the last two decades have produced numerous new efforts to direct engineering to human well-being and to environmental and social goals. These efforts may be aimed at making technical and product design more susceptibility to societal values, such as in value-sensitive design (e.g., Friedman et al., 2006) and design for values (e.g., Van den Hoven et al., 2015). And they may be aimed at creating new forms of design for addressing societal goals more directly, such as social design (e.g., Marzano, 2007), nudging (e.g., Sustain and Thaler, 2008) and positive design (e.g., Desmet and Pohlmeyer, 2013). This societal turn is, for sure, to be welcomed and to be developed. In the last two decades design has also evolved to powerful approaches for taking up tasks beyond technology and product development, and the urgency of some societal goals certainly motivates also applying these new 'design thinking' approaches for addressing them. From the perspective of philosophy of technology this turn is to be supported as well because it takes away the grounds for the somewhat repetitive social criticism of technology in philosophy, and replaces this criticism with constructive collaboration between engineering design, design methodology and ethics, as for instance in the design for values effort. ${ }^{1}$ Still, within philosophy, support implies critical assessment and proposing solutions to possible weaknesses. The weakness that I see is an engineering overconfidence in responsible design, which may lead engineers to suspend earlier commitments to society as laid down in, for instance, engineering codes of conduct and ethics. In this contribution I argue that these codes require that engineers are transparent about the goals they want to realise in their designs. In responsible design this transparency is not always offered, and I will analyse which values towards society are then infringed. I submit that transparency will give society a basis to also get confidence in responsible design.

In the next section of this contribution I start by assessing the concept of responsible design. Then in Section 3 engineering codes are introduced and is it argued that they require that engineers are transparent about their goals in responsible design. In Sections 4 and 5 I consider informed consent and accepting blameworthiness in engineering and argue that also these practices require transparency in responsible design. Section 6 is for conclusions.

\section{RESPONSIBLE DESIGN}

Starting the assessment conceptually, one may observe that the concept of responsible design is suggesting a narrative in which engineering is evolving from an earlier period of irresponsible or aresponsible practices to its current commitment to do good with design. This narrative is easily substantiated with further characterisations and illustrations. Engineers from the twentieth century are then portrayed as professionals who have the technological and design expertise to solve problems and carry out tasks, and do so as ordered by their superiors or paying clients. And through their enthusiasm for technology or through the subservience they project on their profession, such engineers do their designing without paying much attention to the objectives the ordering superiors or clients may have. Such irresponsible or a-responsible engineers are by the narrative however characters of the past. They are giving way to the socially more engaged engineers of today, who take up their own responsibility for the needs in and goals of society as, for instance, laid down in the UN Sustainable Development Goals.

This narrative, although attractive by presenting societal improvement of engineering, is however too simplistic to be true. It moreover glosses over three observations relevant when considering responsible design. The first observation is that also in earlier periods engineers had their commitments to society. The earlier mentioned movement of participatory design, for instance, started in the middle of the twentieth century. And many engineers in that century have invested their skills and energy in design for socially engaged goals as saving the environment and helping developing countries. More traditional engineers in the twentieth century regularly presented their profession as driven by the aims of society (e.g., Florman, 1996), and some even proposed to directly take up social

\footnotetext{
${ }^{1}$ The Delft Design for Values Institute; http://designforvalues.tudelft.nl/
} 
problems with technology, as for instance Weinberg (1966). A second observation is that engineering has went at the end of the twentieth century through processes of bringing its practices more in line with society by adding also responsibility to people and planet to the obligations of engineers. These obligations were laid down in, for instance, codes of conduct and ethics as formulated, adopted and applied by professional engineering societies. The third observation is that, despite the first two, current engineers can operate in an equally compromised way as the irresponsible or a-responsible engineers the narrative positions in the past; the (non-ethical) computer hackers of today, as say the programmers at Cambridge Analytica, are as disconnected from societal values as the Wernher von Brauns of the twentieth century.

When acknowledging these three observations within the narrative, the image of social improvement may be saved by arguing that responsible design emerged out of the observed development towards more societal commitment, and that the creation of the restrictive engineering codes supported this emergence. Yet, with the third observation it can be concluded that engineering design is currently by no means always responsible. Hence, the development towards responsibility in engineering as advanced by the narrative should be qualified; it is not a generally shared development, which makes it important to continue imposing codes of conduct and ethics, and similar restrictions. Moreover, an additional ground for drawing this latter conclusion is that responsible design as it is currently emerging needs protection against overconfidence in the successes it may bring. Some of the earlier movements within engineering to serve societal goals stalled, leading to cynical backlash in society. The mentioned Weinberg (1966), for instance, introduced the concept of a technological fix, being a technological intervention that addresses a social problem by eliminating or circumventing it (Weinberg's examples include, first, overcoming poverty through increasing production of goods by technology rather than through social measures for arriving at a more even distribution of the existing goods; second, reducing traffic deaths by making cars saver rather than through teaching people to drive more carefully; but, third, also the more painful suggestion to avoid race riots at hot, humid weather by handing out air conditioners and free electricity to the people initiating the riots). This social use of technology failed however in spite of, or maybe due to, its grand claims, and the term 'technological fix' acquired subsequently the meaning of a naïve engineering intervention that typically brings more social problems than that it solves (e.g., Rosner, 2004). Here I do not want to claim that Weinberg's program would have been a success if it had observed engineering codes (although it certainly would have ruled out some of his more problematic illustrations). Yet I think that societal uses of engineering can fail due to too grand claims and too high confidence in them at the side of engineering. Such overconfidence can lead to an uncritical application of societally engaged engineering, and an equally uncritical rejection by society when successes are not realised. Sticking to engineering codes can be an antidote to this uncritical application.

More specifically, I argue in this contribution that engineering codes require that engineers are transparent about the goals they want to realise in their designs, and that in responsible design this transparency is not always offered. Hence, by an uncritical adoption of responsible design, engineers may violate their earlier commitments to society as laid down in codes. And I submit that providing transparency gives society a basis to also get confidence in responsible design, since it positions engineers in responsible design as respectful, honest, trustful and open to blame for possible harms.

\section{ENGINEERING CODES}

Codes of conducts and codes of ethics as adopted by professional engineering organisations and companies, express the values these organisations and companies uphold, and articulate them in terms of commitments and obligations for the engineers part of the organisations and companies. These commitments and obligations can be formulated with more or less clarity and detailing, and be imposed with more or less rigour. Codes of professional organisations can be compulsory for members, for instance, in countries where engineering is a licenced profession, and be supported by specialised staff members or ethical committees. In other cases codes have a more aspirational role, expressing what members or employees should ideally strive at.

Engineering organisations that have a code of some sort include the European Federation of National Engineering Associations (FEANI), the U.S. National Society of Professional Engineers (NSPE), the Dutch Koninklijk Instituut voor Ingenieurs (KIVI), and the international Institute of Electrical and Electronics Engineers (IEEE), which even has a code of conduct and a code of ethics. And within the 
commercial domain the design agency IDEO has for its employees code-like documents called The Little Book of IDEO and The Little Book of Design Research Ethics.

Not all of these codes require engineers to be transparent about the goals they want to realise with their designs. Substantial parts of the codes deal with how engineers should operate professionally towards their clients and colleagues, such as the code of conduct of the IEEE (2014), and these parts provide no basis to argue for transparency. Codes can however also contain obligations towards users and society, and these obligations give bases for the argument. I mention here three of such obligations and then give for each of them the argument. The first obligation is that engineers should show respect to the values of the societies they work in. The second is that engineers should explain to users and society how technologies, products and services work, and disclose their possible consequences. The third obligation is that engineers should not deceive the public. In my arguments I assume that the designs concerned are not harmful to users, since for harmful designs codes demand that engineers warn the public and thus be transparent about what the designs do. Hence, for establishing that the three mentioned obligations also require engineers to be transparent, I assume that harm is not involved (in Section 5 about blameworthiness I return to the possibility that designs are harmful).

Consider, first, respect for the values of societies in which engineers work. The FEANI (2006) position paper on its code of conduct contains an (unnumbered) statement that says:

Individual engineers have a personal obligation to act with integrity, in the public interest, and to exercise all reasonable skill and care in carrying out their work.

In so doing engineers:

[...]

Shall respect the personal rights of people with whom they work and the legal and cultural values of the societies in which they carry out assignments

[..]

And the KIVI (2018) code of ethics states similarly:

8. We shall respect the cultural values and the inhabitants of the countries we work in.

The KIVI code explicates this obligation in terms of wearing "appropriate clothing" and showing respect for "sacred places and rites", suggesting that what is meant here is respect for the cultural values of foreign countries the engineer is working in. Yet one can argue that this respect that FEANI and KIVI call for should be shown in all countries. For societies, foreign or at home, where openness in action and communication is valued, it then follows that engineers should be transparent about the goals they design for.

This requirement of transparency may seem trivial and unsubstantial in the case of responsible design since this type of design is by construction aimed at realising societal goals stakeholders agree with. Hence, one may rebut that requiring transparency is spurious for responsible design. That transparency is not a trivial requirement can be illustrated with two cases of responsible design where not revealing the goals designed may be taken as part of the design since not revealing these goals is beneficial to the effectiveness of the designs. The first example is one of social design for social ties in neighbourhoods in the Dutch city of Rotterdam (Tromp and Hekkert, 2016). The second is the design of cafeteria for nudging people to eat less and healthier (Thaler and Sunstein, 2008, pp. 1-4).

The example from social design is design for strengthening the social ties in neighbourhoods. This design consists of a new ritual for children for celebrating their transition from kindergarten to primary school. The ritual involves a big slide that is positioned from the outside against the school building and by which the children can "leave" the kindergarten domain through a window at the first floor. The smart catch of this ritual is that it is oriented at the children but through them also at the parents. The slide is indeed big. It reaches to the first floor of the school building and it has to be manoeuvred in front of the right window. Hence, positioning the slide takes an effort and the parents of the children are asked to deliver this effort. The collaboration that this requires among the parents, and their joint presence at the ritual of their children, is now meant to foster the emerging of social ties between the parents and thus in the neighbourhood they live in.

The cafeteria designed for letting people eat less and healthier is a paradigmatic example by which the potential of nudging for achieving (societal) goals is illustrated (Thaler and Sunstein, 2008). The basic idea behind nudging is that by changing the way in which choices are presented to people, i.e., by changing the choice architecture, people can be stimulated though not forced to make these choices in a manner that on average is leading to outcomes that realise societal goals. For instance, by changing the display of food in cafeteria, people can be nudged to choose healthier products. The vegetables and 
salads can be put up front and in the beginning of the display and near the check-out, and the deepfried products and sweets can be put a bit more out of sight.

Having social ties in neighbourhoods may be judged as acceptable in most societies, and so is eating healthy. Hence, being transparent about these goals in responsible design seems a requirement that is easily met and even spurious. Yet, in the two cases transparency may harm effectiveness of the designs. Informing the parents of the children that the ritual is also meant to bring the parents together, and telling hungry customers that a cafeteria is organised in a way that it is more difficult to get the fried food, may backfire and trigger opposite behaviour, specifically in the case of the cafeteria. Yet, when not informing the parents or customers, these cases of responsible design are violating the codes of FEANI and KIVI, since openness is a value in the city of Rotterdam and in many organisations the cafeteria are for.

Consider, second, obligations that engineers should explain technologies, products and services to users and society, and disclose possible consequences. The IEEE (2018, section 7.8) code of ethics includes such an obligation, since it contains the call:

5. to improve the understanding by individuals and society of the capabilities and societal implications of conventional and emerging technologies, including intelligent systems;

And the KIVI (2018) code of ethics says:

3. We shall contribute to clear communication in reference to technical products and technologies with regard to the application and possible negative effects.

The results of responsible design have societal implications by their applications. Hence, both codes advance an obligation to foster understanding of how responsible designs work and to communicate clearly about its applications. That is, if a cafeteria is designed to nudge customers to eat less and healthier, this should be told to the customers.

The code of ethics from the NSPE gives most direct support to transparency in engineering. Consider, third, deceit. The fifth fundamental canon of the NSPE (2018b) code of ethics reads:

5. Avoid deceptive acts.

And the third professional obligation is:

3. Engineers shall avoid all conduct or practice that deceives the public.

a. Engineers shall avoid the use of statements containing a material misrepresentation of fact or omitting a material fact.

[..]

Not informing the public about what goal a technology, product of service is meant to realise may taken as such deceit, since in responsible design the designers know these goals. Hence, being transparent about this goal is an obligation of engineers to the public by the NSPE code of ethics. The designers of the kindergarten ritual with the slide should inform the parents that the ritual creates social ties between them. Not doing so may be seen as an innocent white lie, yet the NSPE makes clear that engineers are not expected to engage in such lies. The NPSE added 25 questions for its members to test their knowledge of professional ethics, and the fifth question reads (NPSE, 2018a):

5. Engineers shall not be required to engage in truthful acts when required to protect the public health, safety, and welfare.

NPSE's answer is "False - see NSPE Code of Ethics I.5.", referring back to the fifth fundamental canon that I cited above.

For exploring what values are at stake in providing transparency in responsible design, one can have a look at The Little Book of IDEO and The Little Book of Design Research Ethics from the design agency IDEO $(2013 ; 2015)$. These two guides do not have the status of imposed codes but are more internal documents describing how IDEO employees should operate within the company and how they should do design research with external persons. These guides are thus not about how IDEO wants to engage with the users of its designs, yet when assuming that IDEO does not aim to treat its users fundamentally different to the persons it does research with, The Little Book of Design Research Ethics does give indirect information about how IDEO intends to engage with users. And with this assumption it can again be argued that responsible design should be transparent.

IDEO gives in The Little Book of Design Research Ethics three values it holds central in its design research. The three values are respect, responsibility and honesty. For realising respect IDEO researchers are asked the question of whether they treat participants in research as people, rather than as subjects. For responsibility researchers have to consider possible harmful consequences of the research for participants and ask their informed consent (I come back to responsibility and informed 
consent in the next sections). For honesty IDEO researchers are asked to check if they do not mislead participants or leave false impressions (IDEO, 2015, pp. 12-18). In the translation of these values in guidelines for design research other values appear. Research should not feel covert or manipulative and participants should be helped to make informed choices, because transparent and respectful conduct helps built good relationships with participants (p. 24). It is acknowledged that sharing information about research may have an influence on the research outcomes, which may allow delaying information yet does not give reason to hold it back (p. 29). Finally respect and sensitivity for cultural differences among societies is emphasised (pp. 37-38).

IDEO's guide to ethical design research thus introduces the values of respect, responsibility and honesty, and shares with engineering codes the intentions to respect cultural differences, to give information and disclose possible consequences, and to avoid deceit. With the assumption that IDEO does not aim at treating research participants and users fundamentally different, one can argue that IDEO also wants to respect cultural differences towards its users, give the users information and disclose possible consequences, and to avoid deceit. By the arguments given in this section these three intentions imply transparency in design, so IDEO's guide to ethical design research gives support to the position that responsible design should be transparent with respect to the goals it designs for. That transparency will express to users the values of respect, responsibility and honesty.

\section{INFORMED CONSENT}

Engineering codes contain obligations to communicate possible risks and negative consequences of technologies, products and services, and this can be taken as part of a more encompassing obligation advanced by engineering ethics to seek informed consent (e.g., Van de Poel and Royakkers, 2011, pp. 231-232). And when informed consent is accepted as an obligation to engineering, it can again be argued that responsible design should be transparent with respect to the goals it aims to realise.

Informed consent is a central obligation in medical ethics and, as witnessed by IDEO's Little Book of Design Research Ethics, in research ethics: patients or participants to research should not be subjected to treatments or experiments before they are informed about the benefits and possible risks, and before they have given their consent. Also in engineering and product development informed consent or elements thereof are adopted. Engineers should not just serve their superiors or clients, but also identify other direct and indirect stakeholders to their designs, inform them and take their values and interests into account. This requirement is in play in ICT with all the agreements that are presented to users of search machines, websites and apps for accepting possible processing and sharing of the data that users leave behind when using the software. This requirement is also incorporated in the design method of value-sensitive design (Friedman et al., 2006) through the conceptual investigation phase in which designers explicitly explore which stakeholders are involved in a design and how they are affected. In participatory design values and interests of stakeholder are the basis for and of design (e.g., Van der Velden and Mörtberg, 2015).

One can again deny that informed consent needs to be required in responsible design. A minimal interpretation of informed consent in engineering is that it requires communicating only the risks of a technology, product or service to stakeholders, and asking for their acceptance of these risks. And because responsible design is not meant to be harmful, as I also assumed above for the sake of argument, it follows that there are no risks for which informed consent has to be sought. This counterargument may be rejected if responsible design is in some cases actually harmful, and in the next section I consider such cases. Moreover, one can point out that informed consent should not be interpreted in this minimal way. Informed consent is a requirement to communicate both the negative and positive impact of technologies, products and services to stakeholders. Accounts of informed consent in medicine support this wider interpretation. The code of medical ethics from the American Medical Association (AMA, 2018, Opinion 2.1.1) states, for instance, that physicians should communicate also the advantages of medical interventions:

Informed consent to medical treatment is fundamental in both ethics and law. Patients have the right to receive information and ask questions about recommended treatments so that they can make well-considered decisions about care. Successful communication in the patient-physician relationship fosters trust and supports shared decision making. 
The process of informed consent occurs when communication between a patient and physician results in the patient's authorization or agreement to undergo a specific medical intervention. In seeking a patient's informed consent [..] physicians should:

[..]

(b) Present relevant information accurately and sensitively, in keeping with the patient's preferences for receiving medical information. The physician should include information about:

(1) the diagnosis (when known);

(2) the nature and purpose of recommended interventions;

(3) the burdens, risks, and expected benefits of all options, including forgoing treatment.

[..]

Accepting this wider interpretation of informed consent, and transferring it from medicine via engineering to responsible design would mean that the nudging cafeteria should be presented in a way that displays their benefits and possible risks to their customers.

A second line of reasoning for arguing against informed consent in responsible design may be based on the negative impact it may have on effectiveness, as mentioned in the previous section. Telling the parents that the kindergarten ritual with the slide is designed for strengthening the social ties between them, may result in the parents declining to help with operating the slide or even denying their children to take part in the ritual, thus blocking that the slide realises its goal. Seeking informed consent indeed may have this negative effect. As noted above, IDEO in its Little Book of Design Research Ethics (2015, p. 29) acknowledges that telling participants too much about the research they participate in may have an influence on the outcomes of that research. And, returning to medicine, administering placebo treatment is effective only when patients do not know that it is a placebo. IDEO and AMA remain however committed to the obligation of informed consent, and respond to the negative impact by exploring ways to seeking informed consent that do not limit effectiveness (too much). IDEO, for instance, still wants to inform its research participants for keeping its honesty, but considers the possibility to delaying that information (p. 29). And AMA (2018, Opinion 2.1.4) emphasises in its code of medical ethics that withholding information can undermine trust patients put in physicians and explores possibilities to seek informed consent about placebo use by informing patients in a more coarse-grained manner:

[..]

Physicians may use placebos for diagnosis or treatment only if they:

(a) Enlist the patient's cooperation. The physician should explain that it can be possible to achieve a better understanding of the medical condition by evaluating the effects of different medications, including the placebo.

(b) Obtain the patient's general consent to administer a placebo. The physician does not need to identify precisely when the placebo will be administered. In this way, the physician respects the patient autonomy and fosters a trusting relationship, while the patient may still benefit from the placebo effect. [..]

Accepting informed consent in responsible design would imply that also engineers should find creative solutions for seeking informed consent in those cases where effectiveness of the design is undermined when stakeholders know the goal designed for. For the nudging cafeteria the AMA approach may work by telling users in a more general way that the cafeteria is designed for health, but not notifying them that the fried food is deliberately hidden in a distant corner. It seems harder to find a creative informed consent strategy for the kindergarten slide. Yet, following the analysis of AMA, by aiming at informed consent from stakeholder, and the transparency that comes with it, engineers can establish relationships of trust with these stakeholders.

\section{BLAMEWORTHINESS}

A second central obligation in engineering ethics is that engineers should take responsibility in developing technologies, products and services. This obligation seems central to responsible design as well, since responsibility for social and environmental issues in our world motivated designers to engage in it. Yet, responsibility comes in flavours, and the responsibility that defines responsible design seems not to cover them all. For unpacking this possibility I use a distinction Van de Poel and Royakkers (2011, pp. 10-21) make between active and passive responsibility. Active responsibility is a forward-looking duty of engineers to envision and take up opportunities to realise something good. 
Passive responsibility is specified as backward-looking accountability, blameworthiness and liability of engineers for their actions when something went wrong. Active responsibility seems to be closest to responsible designand maybe even defining it. Still passive responsibility applies to responsible design too, through codes of conduct and through the law. As a final step I argue that acceptance of blameworthiness in responsible design should motivate engineers to be transparent to their users.

Van de Poel and Royakkers (2011, pp. 10-13) give four conditions that need to apply for holding a person blameworthy for an action or for the consequences of that action:

Wrong-doing: the person by carrying out the action has violated a norm or did something wrong.

Causal contribution: the person must have made a causal contribution to the action or consequences thereof.

Foreseeability: the person must have been able to know the consequences of his or her action.

Freedom of action: the person must have had freedom in doing the action.

Engineers in responsible design will not meet the first condition of wrong-doing when one assumes that responsible design is not harmful. So for arguing that they may be blameworthy, it should be explored whether responsible design can be harmful. When responsible design is taken as design in which societal goals are realised, possible harm can be done to persons who do not endorse those goals. Let us return to the kindergarten slide and the nudging cafeteria to find possible cases. The slide is meant for stimulating social ties, so persons for whom having such ties is considered to be problematic may be harmed. One can think of persons who for their privacy or security are staying out of the public domain, say, celebrities and persons in legal protection schemes. Or, generalising from the slide and the parents it targets, people whose social contacts are monitored, as children by their parents and persons with legal constraining orders by society. For all such persons, technologies, products and services that seduce them to social ties with others may be harmful. Think, for instance, about the detrimental social relations (bullying, sexting) that children can be seduced to by social media. The nudging cafeteria in turn can be harmful to, for instance, people who need to eat much. Consider members of the university sport team. If football players or marathon runners are through nudging systematically eating less at their university cafeteria than needed to stay fit, they are harmed. So consider the situation in which responsible design can be harmful for specific persons and that it is not transparent with respect to the goals it aims to realise. Consider a product $\mathrm{P}$ designed by engineer $\mathrm{E}$ to realise goal $\mathrm{G}$, and let $\mathrm{U}$ be a user for which realisation of $\mathrm{G}$ is harmful. One can then give a general argument that in this situation the user $\mathrm{U}$ is not blameworthy for the harm, while the designing engineer $\mathrm{E}$ is. If $\mathrm{U}$ decided in freedom to use the product $\mathrm{P}, \mathrm{U}$ meets only three of the four conditions of blameworthiness since $\mathrm{U}$, by lacking information that $\mathrm{P}$ realises goal $\mathrm{G}$, could not foresee that the use of P led to G. The engineer E does however meet all four conditions. Wrong-doing is met because $\mathrm{U}$ realising $\mathrm{G}$ through $\mathrm{P}$ led to harm to $\mathrm{U}$. The engineer $\mathrm{E}$ made a causal contribution to this harm by making the product $\mathrm{P}$ available. This harm can be taken as foreseeable for the engineer $\mathrm{E}$ since it is part and parcel to design that $\mathrm{E}$ explored what impact product $\mathrm{P}$ can have on different groups of users. Finally the freedom of action condition is met since engineers in general have the possibility to adjust or leave a project.

In the alternative situation in which responsible design is transparent with respect to the goals it realises, the verdict reverses. The user $U$ becomes then blameworthy for the harm since now $U$ meets also the condition of foreseeability: by the transparency that $\mathrm{P}$ is meant to realise $\mathrm{G}, \mathrm{U}$ has information to deduce that using $\mathrm{P}$ would lead to G. The engineer $\mathrm{E}$ in turn stops in general to be blameworthy for the harm done to $\mathrm{U}$ because $\mathrm{E}$ can in general not foresee that $\mathrm{U}$ still decides to use the product given that $\mathrm{U}$ has information that this use realises a goal $\mathrm{G}$ that is harmful for $\mathrm{U}$. With transparency the condition of foreseeability does not apply to the engineer E.

As said in Section 3, codes require that engineers should warn the public when technologies, products or services have negative consequences. And by engineering ethics and by law engineers can be held blameworthy for these consequences. Acceptance of these obligations supports again the position that in responsible design engineers should be transparent to users about the goals that are realised by technologies, products and services. This time for showing that engineers in responsible design accept blame for possible harms. 


\section{CONCLUSIONS}

In this contribution I considered the emergence of responsible design in engineering, as visible in efforts as value-sensitive design, design for values, social design, nudging and positive design. This emergence is to be welcomed and supported, also by assessing and strengthening it. The weakness I have discussed was overconfidence in responsible design, which may lead engineers to suspend earlier commitments to society. I have focussed on engineering codes of conduct and ethics, the engineering practice of seeking informed consent with stakeholders, and the obligation to take blame for possible harms. And an argument was given that these commitments of engineers to society lead to the requirement that engineers should be transparent about the goals they intend to realise with their responsible designs. I have given a case of social design and a case of nudging for showing that responsible design need not always offer this transparency to stakeholders.

There are two reasons to insist that responsible design should provide this transparency. The first is that engineering codes and commitments to seeking informed consent and taking blame still hold, also for responsible form of design. The second is that providing transparency can support the acceptance of responsible design by society. Codes, informed consent and taking blame are in engineering (and medical) codes derived from values such as respect, honesty and trust, hence giving transparency positions engineers in society as subscribing to these values.

It was acknowledged that giving transparency about goals may hamper the effectiveness of responsible design. And the position advanced in design research and medical ethics was discussed that this disadvantage should not trump transparency; honesty and trust are reasons to stick to transparency and to look for alternative effective designs or alternative ways for giving that transparency.

Three final remarks are in order. The first is that I just gave two cases of responsible design in which engineers have reason to not giving transparency. In the majority of other responsible design cases engineers may be transparent and naturally be committed to all other social and ethical values and practices.

Second, it may be argued that some forms of responsible design are not part of engineering proper, and this are not subjected to engineering codes of conduct or to other engineering commitments to society. Nudging, for instance, does not have a background in engineering and product development. Still, when accepting this argument, there may be other ethical or social grounds to require transparency. Sunstein in his $(2015$, p. 450) discussion of ethical concerns about changing choice architectures by nudges does take distance of some ethical concerns. But he also concludes that transparency is key for developing nudging:

[..] To make progress, ethical concerns must be brought into close contact with particular examples. It is true that any alterations in choice architecture, including those that preserve freedom, can run into serious and even convincing ethical objections-most obviously, where the underlying goals are illicit. But where the goals are legitimate, nudges are less likely to run afoul of ethical constraints, not least when they promote informed choices [..]. Transparency and public scrutiny are important safeguards, especially when public officials are responsible for nudges and choice architecture. Nothing should be hidden or covert.

Finally, one can note that being transparent in engineering is currently just the default. Food products contain ample information about their ingredients, pharmaceutical products contain ample information about possible side effects, and electrical appliances tell how much energy they consume. Being transparent with respect to the goals of design is therefore a natural extension from giving more physical and technical information to also giving information about the impact on your personal and social behaviour. Rituals and cafeteria can be presented with their impact, as can other designs. From giving the ecological footprints of products, to announcements that cctv is installed for increasing security, and information that architectural layouts of housing foster particular ways of family life.

\section{REFERENCES}

AMA (2018), Code of Medical Ethics. Opinion 2.1.1 on Informed Consent. Available at: https://www.amaassn.org/delivering-care/informed-consent Opinion 2.1.4 on Use of Placebo in Clinical Practice available at: https://www.ama-assn.org/delivering-care/use-placebo-clinical-practice (accessed 10 November 2018).

Desmet, P.M.A. and Pohlmeyer, A.E. (2013), "Positive Design: An Introduction to Design for Subjective WellBeing”, International Journal of Design, Vol. 7 No. 3, pp. 5-19. 
FEANI (2006), FEANI Position Paper on Code of Conduct: Ethics and Conduct of Professional Engineers. Available at: https://www.feani.org/publications/position-papers (accessed 11 November 2018).

Florman, S.C. (1996), The Introspective Engineer, St. Martin's Press, New York.

Friedman, B., Kahn Jr., P.H. and Borning, A. (2006), "Value Sensitive Design and Information Systems", In: P. Zhang and D. Galletta, (Ed.), Human-Computer Interaction in Management Information Systems: Foundations, M.E. Sharpe, Armonk, NY, pp. 348-372.

IDEO (2013), The Little Book of IDEO. Available at: https://lboi.ideo.com/ (accessed 11 November 2018).

IDEO (2015), The Little Book of Design Research Ethics. Available at: https://lbodre.ideo.com/download/ (accessed 11 November 2018).

IEEE (2014), IEEE Code of Conduct. Available at: https://www.ieee.org/about/ieee_code_of_conduct.pdf (accessed 11 November 2018).

IEEE (2018), IEEE Policies. Version of October 2018. Available from: https://www.ieee.org/documents/ieee_policies.pdf (accessed 11 November 2018).

KIVI (2018), Code of Ethics. Version of January 2018. Available at: https://www.kivi.nl/uploads/media/5a587110c2160/2018-01\%20Code\%20of\%20Ethics.pdf (accessed 11 November 2018).

Marzano, S. (2007), Flying over Las Vegas, Koninklijke Philips Electronics NV.

NSPE (2018a), Code of Ethics Examination. Available at: https://www.nspe.org/resources/ethics/ethicsresources/code-ethics-examination The answer is available at https://www.nspe.org/resources/ethics/ethics-resources/ethics-exam/answers-references-code-ethics-exam (accessed 11 November 2018).

NSPE (2018b), Code of Ethics for Engineers. Available at: https://www.nspe.org/sites/default/files/resources/pdfs/Ethics/CodeofEthics/Code-2007-July.pdf (accessed 11 November 2018).

Rosner, L. (Ed.) (2004), The Technological Fix: How People Use Technology to Create and Solve Problems, Routledge, New York City, NY.

Sunstein, C.R. (2015), “The Ethics of Nudging”, Yale Journal on Regulation, Vol. 32, pp. 413-450.

Thaler, R.H. and Sunstein, C.R. (2008), Nudge: Improving Decisions About Health, Wealth, and Happiness, Yale University Press, New Haven, CT.

Tromp, N. and Hekkert, P. (2016), “Assessing Methods for Effect-Driven Design: Evaluation of a Social Design Method", Design Studies, Vol. 43, pp. 24-47.

Van de Poel, I. and Royakkers, L. (2011), Ethics, Technology and Engineering: An Introduction, WileyBlackwell, Chichester.

Van den Hoven, J., Vermaas, P.E. and Van de Poel, I. (2015), Handbook of Ethics, Values and Technological Design, Springer, Dordrecht.

Van der Velden, M. and Mörtberg, C. (2015), "Participatory Design and Design for Values”, In: J. Van den Hoven, P.E. Vermaas and I. Van de Poel, (Ed.), Handbook of Ethics, Values and Technological Design, Springer, Dordrecht, pp. 41-66.

Weinberg, A.M. (1966), “Can Technology Replace Social Engineering?”, Bulletin of the Atomic Scientists, Vol. 22 No. 10 , pp. $4-8$. 